Article - Food/Feed Science and Technology

\title{
Growth and Differentiation Factor-9 Supplementation Affects Viability and Morphology of Preantral Follicles in Equine Ovarian Fragments During Short-term in vitro Culture
}

\section{Polyana Carolina Marino ${ }^{1}$}

https://orcid.org/0000-0002-0829-9225

Camila Bizarro-Silva ${ }^{*}$

https://orcid.org/0000-0003-0230-924X

\section{Isabela Búfalo ${ }^{1}$}

https://orcid.org/0000-0003-1832-1534

Camila Oliveira Rosa ${ }^{1}$

https://orcid.org/0000-0002-2721-0652

\section{Gustavo Romero Gonçalves ${ }^{1}$}

https://orcid.org/0000-0003-1467-1406

Livia Aires Lisboa ${ }^{1}$

http://orcid.org/0000-0001-9161-2982

\section{Marcelo Marcondes Seneda ${ }^{1}$}

https://orcid.org/0000-0002-5097-5119

${ }^{1}$ University of Londrina, Laboratory of Animal Reproduction, Paraná, Brazil.

Received: 2018.07.06; Accepted: 2019.08.07.

*Correspondence: camilabizarros@gmail.com; Tel.: +55-43-33715622 (C.B.S.); Laboratory Animal Reproduction, DCV, CCA, UEL, Londrina, PR 86051-990, Cx. Postal: 10.011, Brazil.

\section{HIGHLIGHTS}

- We evaluated GDF-9 on the in vitro culture of equine follicles.

- Concentrations of 0,50, 100 and $200 \mathrm{ng} / \mathrm{mL}$ the GDF-9 were tested for for 2 or 6 days.

- Based on histology the morphology and the integrity of the follicles were evaluated.

- $\quad$ GDF-9 presented a dynamic effect on the equine follicles cultured in vitro. 
Abstract: This study aimed to evaluate different concentrations of growth and differentiation factor-9 (GDF-9) on the development and maintenance of equine preantral follicle morphology during short-term in vitro culture. Ovaries $(n=5)$ from five mares were collected from a local slaughterhouse and transported to the laboratory, where nine fragments $(5 \times 5 \times 1 \mathrm{~mm})$ were procured from each ovary. One fragment from each was immediately fixed and submitted for histological analysis (control group; D0). The other eight fragments were cultured in situ for two (D2) or six (D6) days in MEM+ or MEM+ supplemented with GDF-9 at different concentrations (i.e., 50, 100 and $200 \mathrm{ng} / \mathrm{mL}$ the GDF-9). After culturing with different concentrations of GDF-9 for 2 or 6 days, the fragments were processed for histological analysis. After two days of cultivation, we observed an increase in the percentage of developing follicles for 0 (MEM+), 50, 100 and $200 \mathrm{ng} / \mathrm{mL}$ GDF-9 compared to control (D0; $\mathrm{P}<0.05$ ). When we evaluated all treatments that preserved follicular integrity, the GDF-9 concentration of $100 \mathrm{ng} / \mathrm{mL}$ presented results superior to those of the other cultures $(P<0.05)$. While, at six days of culture, the concentration of $200 \mathrm{ng} / \mathrm{mL}$ of GDF-9 appeared to be more efficient in providing development compared to MEM+ $(\mathrm{P}<0.05)$. The percentage of morphologically intact follicles in the 6 days culture samples treated with $50 \mathrm{ng} / \mathrm{mL}$ of GDF-9 indicated that this concentration was effective in maintaining the integrity of the follicle $(P<0.05)$. We conclude, therefore, that graduated GDF-9 addition to the medium ensure follicular development and is sufficient maintain the architecture.

Keywords: Assisted Reproduction; GDF-9; Mare.

\section{INTRODUCTION}

The ability to grow immature oocytes in vitro and then recover preantral follicles dramatically increases the availability of fertilizable oocytes for assisted reproduction techniques. Regarding the limited efficacy of assisted reproductive technology in mares, follicular loss is a significant naturally occurring obstacle. Approximately $99 \%$ of follicles present in the preantral reserve pool are destined for follicular atresia, in which the majority of the follicular population does not complete the ovulation process $[1,2]$.

In vitro culture is a biological technique that allows preantral follicular maturation in vitro by the use of an ideal culture medium composed of several substances that modulate follicular dynamics $[3,4]$. Some of these substances, such as antibiotics, buffers, nutritional substrates, protein sources, antioxidants, hormones and growth factors, are added to favor cell nutrition and maintain the integrity of the cells to avoid degenerative processes.

Growth factor supplementation of the medium may contribute to follicular growth and maturation. In equine species, few studies have focused on the in vitro culture of preantral follicles with the addition of growth factors, especially growth and differentiation factor-9 (GDF-9). This growth factor assists in the proliferation of granulosa and theca cells, contributes to the growth of primary follicles and promotes the maintenance of follicular viability $[5,6]$. Furthermore, GDF-9 promoted the survival and continuation of follicular development to the secondary stage in goats [7,8]. GDF-9 is a protein secreted by the oocyte and is considered a potent regulator of ovarian activity, stimulating the proliferation and maintenance of follicular cells. The knockout of GDF-9 can cause infertility in female transgenic and block the development of preantral follicles [9,10]. Its inclusion in culture media has proven to be effective in promoting the development of primordial follicles in goats, rodents, and humans [5,11-12]. In contrast, the information of this substance for the equine follicles is scarce.

The development of an ideal preantral follicle culture system can potentially provide large numbers of oocytes $[2,13]$. Thus, great interest has been shown in its application for animal breeding biotechnology for equine species, in addition to accelerating genetic gains, preantral follicle culture could lead to improved birth rates for animals with subfertility [14].

Despite the great interest in this technique, it is difficult to obtain enough material for the development of this research in horses. Thus, it is suggested the use of ovaries from mares 
that are sacrificed or from imminent death and by surgical methods such as biopsies and ovariectomies [2,13]. Another alternative would be to obtain these ovaries in slaughterhouses, which are scarce all over the world [13]. Based on this information, the objective of the present study was to evaluate the effects of different GDF-9 concentrations on the in vitro culture of preantral follicles in the equine species.

\section{MATERIAL AND METHODS}

\section{Collection and transport of ovaries}

Ovaries were collected from undefined breed mares $(n=5)$ in seasonal anestrus and without signs of cyclicity (i.e., absence of corpus luteum and follicles with diameters greater than $10 \mathrm{~mm}$ ), of unknown breed, age, and body condition score, from the local

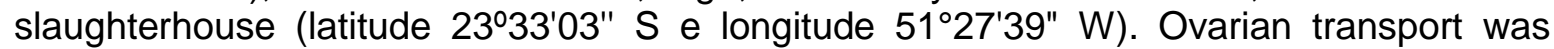
performed according to Gomes et al. (13), briefly, in a thermal container containing modified PBS solution (Cultilab, Campinas, SP, Brazil) with penicillin $(200 \mathrm{IU} / \mathrm{mL})$ and streptomycin $(200 \mathrm{mg} / \mathrm{mL})$ at $4^{\circ} \mathrm{C}$; the approximate time to reach the laboratory was 40 minutes.

\section{Ovarian processing}

In the laboratory, the ovaries were washed with $70 \%$ alcohol and modified PBS solution at $4^{\circ} \mathrm{C}$. Using a scalpel and scissors, the ligaments and connective tissue were removed, and then a sagittal cut in the greater curvature of the ovary was performed to yield two hemi-ovaries. Ovarian fragments measuring $5 \times 5 \times 1 \mathrm{~mm}$ were obtained from 5 animals $(n=9$ fragments from each) through sections of the parenchyma in the region equidistant from the major and minor curvatures of the ovary. The fragments were then washed with PBS solution, and one of them was fixed in Bouin as the experimental control $(D=0)$, while the other fragments were sent for in vitro culture of the preantral follicles.

\section{In vitro culture preantral follicles}

The ovarian fragments $(n=8)$ were individually cultured in 24-well culture plates containing $1 \mathrm{~mL}$ of base medium $(\mathrm{MEM}+)$ or $\mathrm{MEM}+$ supplemented with different concentrations of GDF-9 (50, 100 and $200 \mathrm{ng} / \mathrm{mL}$ - Figure 1). MEM+ was composed of MEM (Gibco BRL, Rockville, MD, USA - osmolarity $300 \mathrm{mOsm} / \mathrm{L}, \mathrm{pH}$ 7,2, $47 \mathrm{~mL}$ ), with added penicillin $(200 \mathrm{IU} / \mathrm{mL})$, streptomycin $(200 \mathrm{mg} / \mathrm{mL})$, bovine serum albumin $(1.25 \mathrm{mg} / \mathrm{mL})$, insulin $(6.25 \mathrm{mg} / \mathrm{mL})$, transferrin $(6.25 \mathrm{mg} / \mathrm{mL})$, selenium $(6.25 \mathrm{mg} / \mathrm{mL}), 0.23 \mathrm{mM}$ pyruvate, 2 $\mathrm{mM}$ glutamine, and $2 \mathrm{mM}$ hypoxantine. The fragment-containing plates were routed to the oven at $39^{\circ} \mathrm{C}$ and exposed to ambient air with 5\% CO2 and saturated humidity for 2 (D2) or 6 (D6) days. The culture medium was exchanged every 2 days. After completion of the culture, the fragments were fixed in Bouin and processed for classical histology to evaluate the growth and morphology of the preantral follicles. 


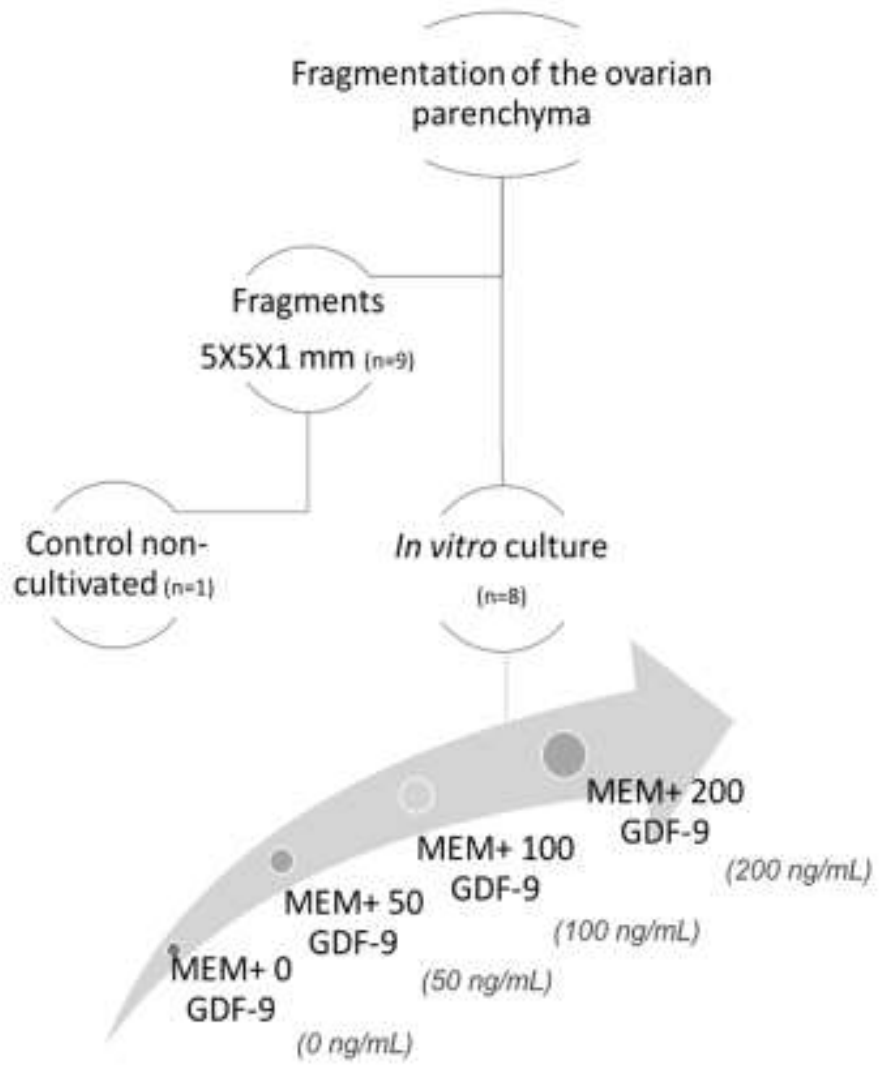

Figure 1. Experimental protocol for in vitro culture of equine preantral follicles at variable GDF-9 concentrations.

\section{Histological processing}

The ovarian fragments (control, D2 and D6) were fixed in Bouin for 24 hours and then maintained in $70 \%$ alcohol until the beginning of histological processing. When destined for histology, the fragments were dehydrated in ethanol, diaphanized in xylol, embedded in paraffin blocks, serially cut at $5 \mu \mathrm{m}$ intervals using a rotary microtome (Leica ${ }^{\circledR}$, Wetzlar, Germany), fixed to histological slides and stained using the Periodic acid- Schiff (PAS) and hematoxylin. To avoid counting the same follicle more than once, only the sections in which the oocyte nucleus was observed were considered.

\section{Follicular Classification}

Regarding follicular development, preantral follicles were classified as primordial and developing (primary and secondary). The primordial follicles were those that displayed a single layer of granulosa cells, with a pavement-like appearance, surrounding the oocyte. The developing follicles were considered primary follicles when they had a layer of cuboidal granulosa cells surrounding the oocyte and considered secondary follicles when they had two or more layers of (cuboid) granulosa cells $[13,15]$.

As for follicular morphology, the follicles were classified as intact or degenerate. Briefly, follicles classified as degenerate had a pyknotic nucleus, granulosa cell disorganization, cytoplasmic retraction, chromatin condensation or total destruction of follicular components, whereas normal follicles exhibited structural integrity [16]. 


\section{Statistical analysis}

Statistical analysis was performed by the Action 3.1 version of $R 3.0 .2$ software (Campinas, SP, Brazil). The data were initially submitted to tests for normality of residuals (Shapiro-Wilk) and homogeneity of variance (Bartlett). The mean number of morphologically intact preantral follicles as well as the primordial and developing follicles obtained in both the control samples and in samples with each concentration of GDF-9 supplementation, grown for 2 or 6 days, were submitted to ANOVA and Tukey's test. Findings were considered significant at $\mathrm{P} \leq 0.05$.

\section{RESULTS}

In this experiment, 810 slides were evaluated, containing 2,430 histological sections of 45 ovarian fragments that were obtained from five mares. Of the 271 follicles evaluated, $51.7 \%$ were primordial follicles, $48.3 \%$ were developing, and $70.1 \%$ were intact. The control group had $69.2 \%$ primordial follicles and, of these, $82.2 \%$ were considered intact (Figure 2 ). The distribution of the primordial and developing follicles is shown in Table 1, whereas the morphologically normal follicles are represented in Figure 3.

Table 1. Percentage of primordial and developing follicles evaluated during a 2 or 6 days in vitro culture of equine ovarian fragments treated with minimal supplemented essential medium (MEM+) or $\mathrm{MEM}+$ supplemented with variable GDF-9 concentrations $(50,100,200 \mathrm{ng} / \mathrm{mL})$.

\begin{tabular}{|c|c|c|c|}
\hline $\begin{array}{c}\text { Treatment/ } \\
\text { Cultivation period }\end{array}$ & $\begin{array}{l}\text { Primordial Follicles } \\
\qquad \%(\mathbf{N})\end{array}$ & $\begin{array}{l}\text { Follicles in Development } \\
\qquad \%(\mathrm{~N})\end{array}$ & $\begin{array}{c}\text { Total Follicles } \\
\text { N }\end{array}$ \\
\hline \multicolumn{4}{|l|}{$D O$} \\
\hline Control & $69.2(74)$ & $30.8(33)^{c}$ & $107^{\#}$ \\
\hline \multicolumn{4}{|l|}{$D 2$} \\
\hline MEM+ & $36.8(7)$ & $63.2(12)^{b}$ & $19^{a b}$ \\
\hline GDF-9 50 & $43.9(18)$ & $56.1(23)^{b}$ & $41^{\mathrm{ab}}$ \\
\hline GDF-9 100 & $57.1(4)$ & $42.9(3)$ \# & $7^{b}$ \\
\hline GDF-9 200 & $42.9(24)$ & $57.1(32)^{b}$ & $56^{a}$ \\
\hline \multicolumn{4}{|l|}{$D 6$} \\
\hline MEM+ & $52.4(11)$ & $47.6(10) \mathrm{bc}$ & $21^{\mathrm{ab}}$ \\
\hline GDF-9 50 & $33.3(1)$ & 66.7 (2) \# & $3^{b}$ \\
\hline GDF-9 100 & 0 & $100.0(2) \#$ & $2^{b}$ \\
\hline GDF-9 200 & $6.7(1)$ & $93.3(14)^{a}$ & $15^{\mathrm{ab}}$ \\
\hline
\end{tabular}

$a, b, c$ and within the same column differ statistically $(p<0.05)$ between treatments (control, MEM+, GDF-9 50, GDF-9 100 and GDF-9 200).

\# Values not compared by statistical tests.

For two-day cultivation, specimens treated with different concentrations of GDF-9 and $\mathrm{MEM}+$ maintained higher percentages of developing follicles relative to uncultivated control specimens $(P>0.05$; Table 1). When evaluating the percentage of developing follicles, there was no difference between the GDF-9 concentration treatments; however, the treated cultures showed that they supported the additional development of the cultivated follicles compared to the non-cultivated controls (D0). When we evaluated follicular integrity, the GDF-9 concentration of $100 \mathrm{ng} / \mathrm{mL}$ gave superior results as compared to the other two-day cultures (Figure 3). 

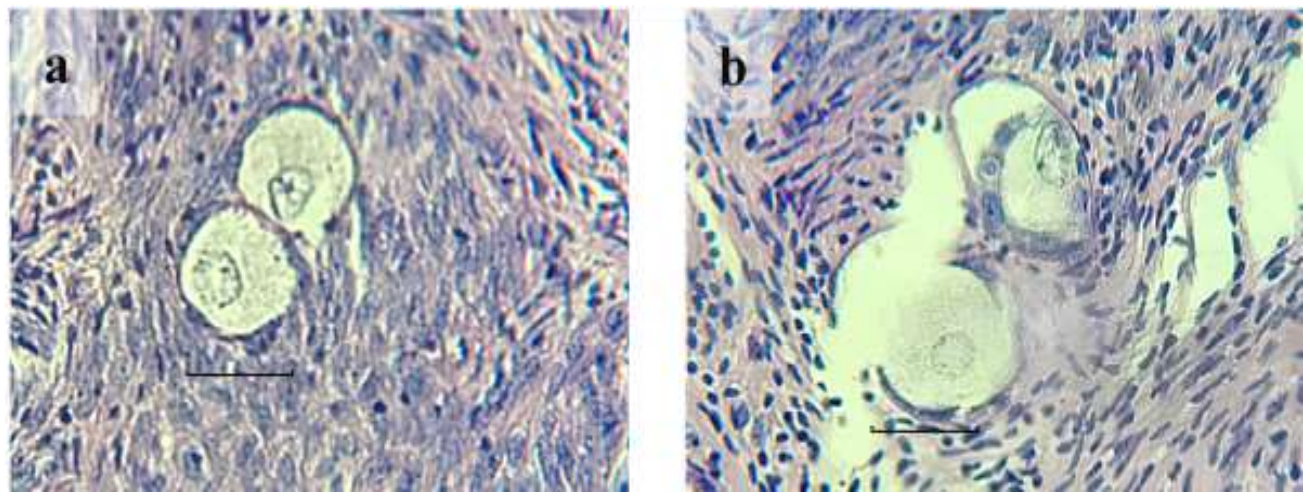

Figure 2. Morphological aspects of preantral follicles grown in vitro. (a) Normal primordial follicles and (b) Abnormal primordial follicles. The sections were stained with periodic acid-Schiff (PAS) and hematoxylin.

When we evaluated the results at 6 days of culture, we observed a representative increase in the percentage of developing follicles present only at the GDF- 9 concentration of $200 \mathrm{ng} / \mathrm{mL}$, relative to the MEM+ control $(P<0.05$; Table 1). The percentage of morphologically intact follicles obtained in the 6-day culture indicated that treatment with 50 $\mathrm{ng} / \mathrm{mL}$ GDF-9 was efficacious in maintaining follicular integrity $(P<0.05$; Figure 3$)$.

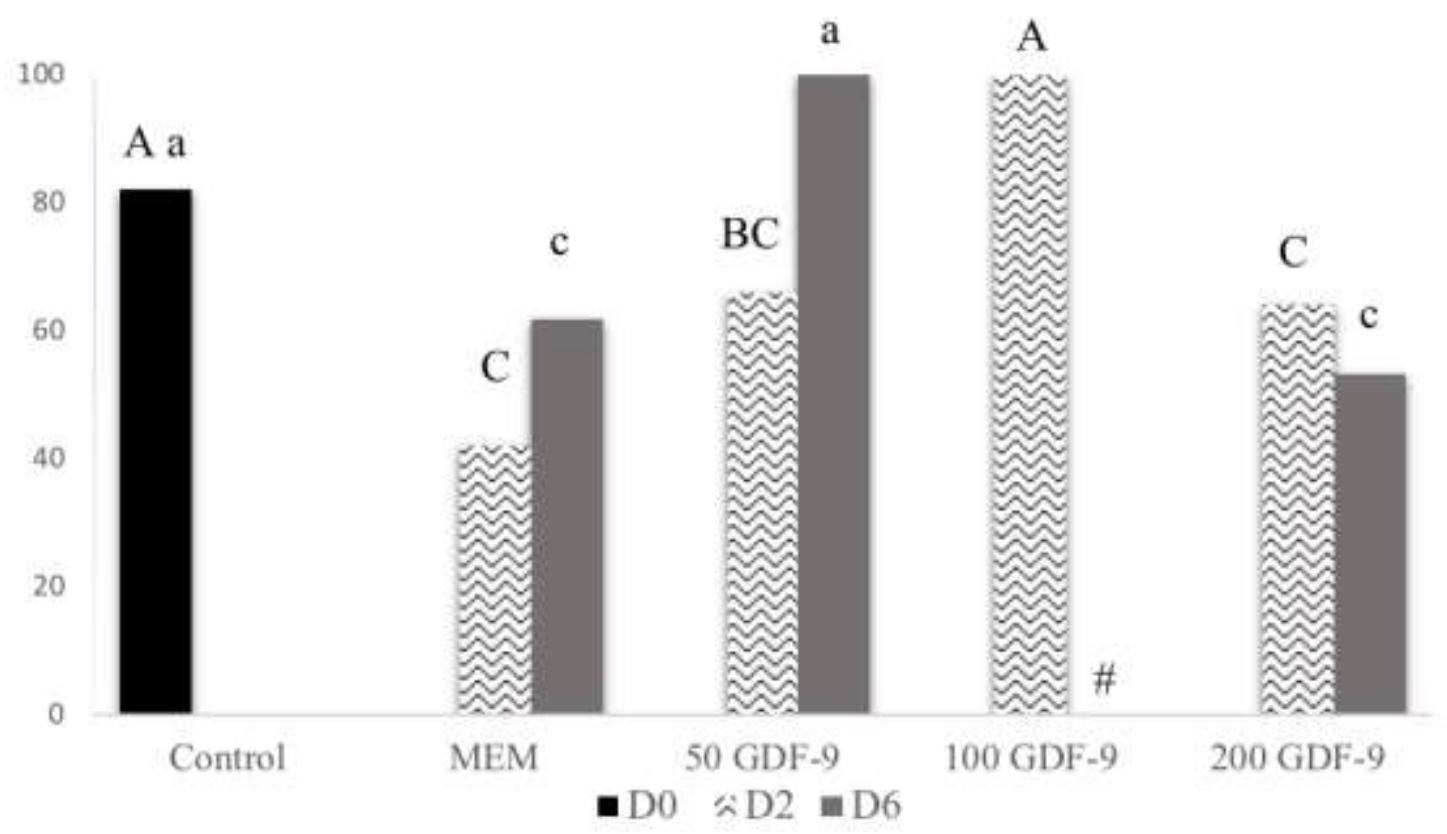

Figure 3. Percentage of total intact follicles in 2 or 6 days (D2 or D6) in vitro culture of equine ovarian fragments in supplemented minimal essential medium (MEM+) or MEM+ supplemented with variable GDF-9 concentrations (50, 100 and $200 \mathrm{ng} / \mathrm{mL}$ ). Values followed by uppercase letters $(A, B)$ differ statistically $(p<0.05)$ between treatments (control, MEM+, GDF-9 50, GDF-9 100 and GDF-9 200) at 2 days of culture. Values followed by lowercase letters $(a, b)$ differed statistically $(p<0.05)$ between treatments (control, MEM+, GDF-9 50, GDF-9 100 and GDF-9 200) at 6 days of culture. Values followed by a \# were not compared by statistical test. 


\section{DISCUSSION}

The present study demonstrated for the first time that the addition of GDF-9 to an in vitro culture of equine preantral follicles has the capacity to promote follicular survival as well as its activation and development.

When evaluating supplementation with different concentrations of GDF-9 for in vitro cultures of ovarian fragments (in situ), we observed (i.e., detected histologically) that on the second day, all culture concentrations of GDF-9 (50, 100 and $200 \mathrm{ng} / \mathrm{mL})$ supported the development of preantral follicles. On the other hand, the six-day cultures revealed that the highest number of developing follicles occurred when cultivated at a GDF- 9 concentration of $200 \mathrm{ng} / \mathrm{mL}$. Similarly, in situ (7 days) goat follicle culture studies identified that a GDF-9 concentration of $200 \mathrm{ng} / \mathrm{mL}$ was essential for primordial follicle activation and progression to more advanced stages of development [7].

GDF-9 plays an important role in growth and follicular development. This growth hormone is part of the superfamily of "growth factors $\beta$ " (TGF $\beta ; 17)$, which are necessary and vital for follicular activation and growth. Although the factors and mechanisms that involve folliculogenesis are not well elucidated, it is possible to affirm that GDF-9 plays an important role in early folliculogenesis, follicular differentiation and steroid hormone synthesis [18,19]. GDF-9 is so essential that in an experiment with GDF-9-depleted rats and sheep, primordial follicles remained at this stage of development, and these animals became sterile $[8,20]$. Based on these findings and our results, the effect of GDF-9 on in vitro follicular development is confirmed.

It was not possible to observe significant differences between treatments at the second day of cultivation; however, all treatments were developmentally responsive as compared to the uncultivated control (D0). This is because GDF-9 promotes granulosa cell proliferation, cumulus expansion, production of steroid hormones, activation and follicular growth [21, 22].

In this study, it is also presumed that the concentration of $100 \mathrm{ng} / \mathrm{mL}$ of GDF-9 at 2 days of culture achieved a satisfactory result in terms of the maintenance of follicular integrity when compared to the other treatments. In contrast, at 6 days of culture, the adequate concentration to maintain follicular integrity was $50 \mathrm{ng} / \mathrm{mL}$. Similarly, it was found that the concentration of $100 \mathrm{ng} / \mathrm{mL}$ of GDF-9 was required for follicular survival in a culture of follicles isolated from goat ovaries [5]. Furthermore, in vitro in situ cultures of human preantral follicles demonstrated that GDF-9 promoted follicular viability for 14 days as well as the progression of primordial and primary follicles to the secondary stage [11].

As in other studies with preantral follicle cultures, it was difficult to find a high density of preantral follicles compared to other species [bovine: 4, ovine: 23, caprine: 24], even after the removal of internal fragments of the equine ovary. This finding was also reported by Driancourt et al. [25] and in recent investigations by Gonzalez et al. [26], Gomes et al. [27] and Alves et al. [28], who found little quantitative homogeneity of follicles in their evaluated fragments.

\section{CONCLUSION}

Thus, we can conclude that the addition of GDF-9 to the medium, in a graduated way, guarantees improved follicular development as well as the satisfactory maintenance of follicular architecture. Thus, this study corroborates a wider and innovative use of GDF-9 in culture media and opens new horizons for the investigation of other substances and factors that may benefit follicular development. In turn, equine follicular development can be further optimized.

Funding: This research received no external funding.

Conflicts of Interest: The authors declare no conflict of interest. 


\section{REFERENCES}

1. Ireland JJ. Control of follicular growth and development. J Reprod Fertil Suppl. 1987;34:39-54.

2. Haag KT, Magalhães-Padilha DM, Fonseca GR, Wischral A, Gastal MO, King SS, et al. In vitro culture of equine preantral follicles obtained via the Biopsy Pick-Up method. Theriogenology. 2013;79(6): 911-7.

3. Figueiredo JR, Celestino JJH, Faustino LR, Rodrigues APR. In vitro culture of caprine preantral follicles: Advances, limitations and prospects. Small Ruminant Res. 2011;98(1-3): 192-5.

4. Andrade ER, Van Den Hurk R, Lisboa LA, Hertel MF, Melo-Sterza FA, Moreno K, et al. Effects of ascorbic acid on in vitro culture of bovine preantral follicles. Zygote. 2012;20(4):379-88.

5. Almeida AP, Saraiva MVA, Araújo VR, Magalhães DM, Duarte ABG, Frota IMA, et al. Expression of growth and differentiation factor 9 (GDF-9) and its effect on the in vitro culture of caprine preantral ovarian follicles. Small Ruminant Res. 2011;100:169-76.

6. De Los Reyes M, Rojas C, Parraguez VH, Palomino J. Expression of growth differentiation factor 9 (GDF-9) during in vitro maturation in canine oocytes. Theriogenology. 2013;80(6):587-96.

7. Martins FS, Celestino JJH, Saraiva MVA, Matos MHT, Bruno JB, Rocha-Junior CMC, et al. Growth and differentiation factor-9 stimulates activation of goat primordial follicles in vitro and their progression to secondary follicles. Reprod Fert Develop. 2008;20:916-24.

8. Leitão CCF, Costa JJN, Brito IR, Magalhães-Padilha DM, Almeida AP, Figueiredo JR, et al. Effects of GDF-9 and FSH on mRNA Expression for FSH-R, GDF-9 and BMPS in in vitro cultured goat preantral follicles. Braz Arch Biol Techn. 2014;57(2):200-8.

9. Dong J, Albertine DF, Nishimori K, Kumar TR, Lu N, Matzuk MM. Growth differentiation factor-9 is required during early ovarian folliculogenesis. Nature. 1996;383:531-5.

10. Elvin JA, Clark AT, Wang P, Wolfman NM, Matzuk MM. Paracrine actions of growth differentiation factor-9 in the mammalian ovary. Mol Endocrinol. 1999;13:1035-48.

11. Nilsson EE, Skinner MK. Growth and differentiation factor-9 stimulates progression of early primary but not primordial rat ovarian follicle development. Biol Reprod. 2002;67(7):1018-24.

12. Hreinsson JG, Scott JE, Rasmussen C, Swahn ML, Hsueh AJ, Hovatta O. Growth differentiation factor-9 promotes the growth, development, and survival of human ovarian follicles in organ culture. J Clin Endocrinol Metab. 2002;87(1):316-21.

13. Gomes RG, Andrade ER, Lisboa LA, Ciquini A, Barreiros TRR, Fonseca NA, Seneda MM. Effect of holding medium, temperature and time on structural integrity of equine ovarian follicles during the non-breeding season. Theriogenology. 2012;78(4):731-6.

14. Bortot $D$, Zappa $V$. Aspectos da reprodução equina: Inseminação artificial e tranferência de embrião: Revisão de literatura. Rev Cient Elet Med Vet. 2013;21:1-23.

15. Hulshof SC, Figueiredo JR, Beckers JF, Bevers MM, Van den Hurk R. Isolation and characterization of preantral follicles from fetal bovine ovaries. Vet Quart. 1994;16:78-80.

16. Gomes RG, Silva CB, Gonzalez SM, Oliveira RL, Max MC, Lisboa LA, et al. Alpha lipoic acid (ALA) effects on developmental competence of equine preantral follicles in short-term culture. Theriogenology. 2018;105:169-73.

17. Chang $\mathrm{H}$, Brown CW, Matzuk MM. Genetic analysis of the mammalian transforming growth factor-b superfamily. Endocr Rev. 2002;23(6):787-823.

18. Sun R, Lei L, Cheng L, Jin Z, Zu S, Shan Z, et al. Expression of GDF-9, BMP-15 and their receptors in mammalian ovary follicles. J Mol Histol. 2010;41:325-32.

19. Kedem A, Fisch B, Garor R, Ben-Zaken A, Gizunterman T, Felz C, et al. Growth differentiating factor 9 (GDF9) and bone morphogenetic protein 15 both activate development of human primordial follicles in vitro, with seemingly more beneficial effects of GDF9. J Clin Endocrinol Metab. 2011;96(8):E1246-E1254.

20. Galloway SM, McNatty KP, Cambridge LM, Laitinen MP, Juengel JL, Jokiranta TS, et al. Mutations in an oocytederived growth factor gene (BMP15) cause increased ovulation rate and infertility in a dosage-sensitive manner. Nat Genet. 2000;25(3):279-83.

21. Hayashi M, McGee EA, Min G, Klein C, Rose UM, van Duin M, et al. Recombinant growth differentiation factor-9 (GDF9) enhances growth and differentiation of cultured early ovarian follicles. Endocrinol, 1999;140(3):1236-44. 
22. Vitt UA, Hayashi M, Klein C, Hsueh AJ. Growth differentiation factor-9 stimulates proliferation but suppresses the follicle-stimulating hormone-induced differentiation of cultured granulosa cells from small antral and preovulatory rat follicles. Biol Reprod. 2000;62(2):370-7.

23. Lima LF, Rocha RPM, Alves AMCV, Carvalho AA, Chaves RN, Lopes CAP, Báo SN, et al. Comparison between the additive effects of diluted ( $\mathrm{rFSH})$ and diluted/dynamized $(\mathrm{FSH} 6 \mathrm{cH})$ recombinant follicle-stimulating hormone on the in vitro culture of ovine preantral follicles enclosed in ovarian tissue. Complement Ther Med. 2016;25:39-44.

24. Carvalho AA, Faustino LR, Silva CMG, Castro SV, Luz HKM, Rossetto R, et al. Influence of vitrification techniques and solutions on the morphology and survival of preantral follicles after in vitro culture of caprine ovarian tissue. Theriogenology. 2011;76:933-41.

25. Driancourt MA, Paris A, Roux C, Mariana JC, Palmer E. Ovarian follicular populations in pony and saddle-type mares. Reprod Nutrit Develop. 1982;22:1035-47.

26. Gonzalez SM, Silva CB, Lindquist AG, Bufalo I, Morotti F, Lisboa LA, et al. Regional distribution and integrity of equine ovarian pre-antral follicles. Reprod Domest Anim. 2017;52(5):836-41.

27. Gomes RG, Lisboa LA, Silva CB, Max MC, Marino PC, Oliveira RL, et al. Improvement of development of equine preantral follicles after six days of in vitro culture with ascorbic acid supplementation. Theriogenology. 2015;84(5):750-5.

28. Alves KA, Alves BG, Rocha CD, Visona M, Mohallem RFF, Gastal MO, et al. Number and density of equine preantral follicles in different ovarian histological section thicknesses. Theriogenolgy. 2015;83(6):1048-55.

(C) 2018 by the authors. Submitted for possible open access publication under the terms and conditions of the Creative Commons Attribution (CC BY NC) license (https://creativecommons.org/licenses/by-nc/4.0/). 